\title{
Correction to: Inclusion, Equity and Access for Individuals with Disabilities
}

\author{
Santoshi Halder and Vassilios Argyropoulos
}

\section{Correction to:}

S. Halder and V. Argyropoulos (eds.), Inclusion, Equity and Access for Individuals with Disabilities, https://doi.org/10.1007/978-981-13-5962-0

In the original version of this book, the following belated corrections have been made:

In Chapter 14, the names of co-authors "Refilwe Elizabeth Morwane" and "Juan Bornman" have been added along with Dr. Maximus.

In Chapter 30, the name of the co-author "Amy Hackeman" has been changed to "Amy Henkeman".

In Front Matter, biography has been added for the author "Refilwe Elizabeth Morwane".

The updated version of these chapters can be found at

https://doi.org/10.1007/978-981-13-5962-0_14

https://doi.org/10.1007/978-981-13-5962-0_30

https://doi.org/10.1007/978-981-13-5962-0

(C) The Author(s) 2019

C1

S. Halder and V. Argyropoulos (eds.), Inclusion, Equity and Access for Individuals with

Disabilities, https://doi.org/10.1007/978-981-13-5962-0_33 